\title{
Coordinated Geochronology of an Apollo Regolith Fragment
}

\author{
CAROLYN A. CROW ${ }^{1}$, LARS BORG ${ }^{2}$, WILLIAM \\ CASSATA $^{2}$ AND SEAN POMEROY ${ }^{1}$ \\ ${ }^{1}$ University of Colorado Boulder \\ ${ }^{2}$ Lawrence Livermore National Laboratory \\ Presenting Author: carolyn.crow@colorado.edu
}

Coordinating geochronologic analyses of returned samples is important due to the masses required for destructive isotopic analyses, and because of the potential complexity of returned samples. The minimum sample masses defined as mission success criteria for the recently returned, upcoming, ongoing, and previously proposed sample return missions range from 100s of $\mathrm{mg}$ to a few $\mathrm{kg}$. The mass requirements for geochronologic analyses also very greatly, but in some cases is on the order of $10 \mathrm{~s}$ of mg per measurement. In other cases, such as accessory phase geochronology, one must rely on serendipitous discovery of target minerals in thin section or process grams of material to achieve statistically robust results. Further adding to the need to coordinate geochronologic analyses is the potential complex histories of extraterrestrial samples, such as impact breccias from the Apollo collection.

We have undertaken a capability demonstration study to assess if a comprehensive suite of geochronologic analyses can be collected for a $\sim 4 \mathrm{~mm}$ lithic fragment $(12033,638-1)$ separated from an Apollo 12 soil. This fragment was first described by [1] and [2], and is classified as a Th-rich and KREEP-rich impact melt breccia. Zircon ${ }^{207} \mathrm{~Pb}-{ }^{206} \mathrm{~Pb}$ ages were previously collected by [3] and yield a weighted average age of $3920 \pm 13 \mathrm{Ma}$. We have collected additional ${ }^{40} \mathrm{Ar}-{ }^{39} \mathrm{Ar}$ thermochronology and ${ }^{38} \mathrm{Ar}$ exposure ages [4], and $\mathrm{Rb}-\mathrm{Sr}$ and $\mathrm{Sm}-\mathrm{Nd}$ ages for a subsection of the same fragment. The ${ }^{40} \mathrm{Ar}-{ }^{39} \mathrm{Ar}$ thermochronology and zircon ages suggesting the oldest clasts date to at least $\sim 3.8 \mathrm{Ga}$, with significant Ar-degassing due to the Copernicus impact $\sim 860 \mathrm{Ma}$. The ${ }^{38} \mathrm{Ar}$ exposure ages suggest a second excavation event $\sim 130$ Ma. The Sm-Nd system yields an age older than the solar system and the $\mathrm{Rb}-\mathrm{Sr}$ system has an unreasonable initial ${ }^{87} \mathrm{Sr} /{ }^{86} \mathrm{Sr}$, suggesting that the impact melt is unequilibrated. This study demonstrates the advantage of coordinated chronology in deciphering complex samples histories, as well as the challenges that could arise if the masses of returned samples are small.

[1] Zeigler et al. (2006) LPSC XXXVII \#2366

[2] Korotev et al. (2011) GCA 75:1540-1573

[3] Liu et al. (2012) EPSL 319-320:277-286

[4] Crow et al. (2017) LPSC XLVIII \#2823 